\title{
Synthesis of UV-Cured Hyperbranched Polyurethane Acrylate Coatings and Its Corrosion Resistance Revealed by Electrochemistry
}

\author{
Jin Cui ${ }^{1,2}$, Yihe Zhang ${ }^{1, *}$, Xiaoyong $\mathrm{Hu}^{2}$, Paul K. Chu ${ }^{3}$, Falong Wang $^{2}$, Xinke Wang ${ }^{1}$, Yuqing Xu ${ }^{2}$ \\ ${ }^{1}$ Beijing Key Laboratory of Materials Utilization of Nonmetallic Minerals and Solid Wastes, National \\ Laboratory of Mineral Materials, School of Materials Science and Technology, China University of \\ Geosciences, Beijing, 100083, China \\ ${ }^{2}$ School of Biological and Chemistry Engineering, Guangxi University of Science and Technology, \\ Liuzhou 545006, China \\ ${ }^{3}$ Department of Physics and Materials Science, City University of Hong Kong, Tat Chee Avenue, \\ Kowloon, Hong Kong, China \\ *E-mail: zyh@cugb.edu.cn
}

doi: $10.20964 / 110268$

Received: 6 December 2015 / Accepted: 19 February 2016 / Published: 1 April 2016

First generation hyper-branched poly-ester-amine, second generation hyper-branched poly-esteramine, and isophorone diisocyanate-2-hydroxyethylacrylate are first synthesized and the hyperbranched polyurethane acrylate oligomer is subsequently prepared with the second generation hyper-branched poly-ester-amine. Finally, the UV-cured hyper-branched coatings are produced with the hyper-branched polyurethane acrylate oligomers, methyl acrylate, 2-hydroxyethyl methacrylate, and photo-initiator 1173. The structure of the first generation hyper-branched poly-ester-amine, second generation hyper-branched poly-ester-amine, and hyper-branched polyurethane acrylate oligomers, and UV-cured coatings are characterized by FT-IR, TG, and SEM. The corrosion resistance of the hyper-branched coatings is studied electrochemically and compared to conventional coatings. The self-corrosion rate of conventional coatings drops from $28.022 \mathrm{~mm} / \mathrm{A}$ to $17.468 \mathrm{~mm} / \mathrm{A}$ and hyper-branched coatings from $28.022 \mathrm{~mm} / \mathrm{A}$ to $8.061 \mathrm{~mm} / \mathrm{A}$. The hyper-branched coatings have very good thermal properties, corrosion resistance, as well as cross-linking density.

Keywords: UV-curing, hyperbranched coatings, polyurethane acrylate

\section{$\underline{\text { FULL TEXT }}$}

(C) 2016 The Authors. Published by ESG (www.electrochemsci.org). This article is an open access article distributed under the terms and conditions of the Creative Commons Attribution license (http://creativecommons.org/licenses/by/4.0/). 